\title{
Healthcare systems and the sciences of health professional education
}

\author{
R. B. Hays ${ }^{1}$ D . S. Ramani ${ }^{2} \cdot$ A. Hassell ${ }^{3}$
}

Received: 28 July 2020 / Accepted: 27 October 2020 / Published online: 18 November 2020

(c) Springer Nature B.V. 2020

\begin{abstract}
Health professions education is that part of the education system which applies educational philosophy, theory, principles and practice in a complex relationship with busy clinical services, where education is not the primary role. While the goals are clear-to produce the health workforce that society needs to improve health outcomes-both education and healthcare systems continue to evolve concurrently amidst changes in knowledge, skills, population demographics and social contracts. In observing a significant anniversary of this journal, which sits at the junction of education and healthcare systems, it is appropriate to reflect on how the relationship is evolving. Health professions educators must listen to the voices of regulators, employers, students and patients when adapting to new service delivery models that emerge in response to pressures for change. The recent COVID-19 pandemic is one example of disruptive change, but other factors, such as population pressures and climate change, can also drive innovations that result in lasting change. Emerging technology may act as either a servant of change or a disruptor. There is a pressing need for interdisciplinary research that develops a theory and evidence base to strengthen sustainability of change.
\end{abstract}

Keywords Health sciences education - Social contract - Curriculum development · Assessment · Graduate outcomes

\section{Introduction}

The goal of the World Health Organisation is: 'To improve equity in health, reduce health risks, promote healthy lifestyles and setting, and respond to underlying determinants of health' (World Health Organisation 2020). Making progress poses enormous challenges because health outcomes are open to influence from so many factors, both individual and societal. Substantial resources are invested in building stronger societies through improving

\footnotetext{
R. B. Hays

richard.hays@jcu.edu.au

1 College of Medicine \& Dentistry, James Cook University, Townsville, Australia

2 Brigham and Women's Hospital and Harvard Medical School, Boston, MA 02115, USA

3 School of Medicine, Keele University, Newcastle upon Tyne, UK
} 
education and health outcomes, although access to healthcare and education, their cost and their outcomes may vary across populations and nations. Health professions' education provides the workforce, functioning at the convergence of two large fields of knowledge and practice-education and health care. Each is a 'system' in its own right, defined by a set of knowledge, skills and behaviours that shape interactions with participants that include potentially almost every human on the planet. Both systems are demand driven and are so large that they are often among the largest items of national expenditure. Both public and private enterprise models strive for effectiveness and efficiency with so many components and such high economic impact that the terms 'sector' or 'industry' may be more appropriate than 'system' (Rastegar 2004).

Health professions education is a relatively small part of the broader education system. Unlike primary and secondary level education, it is embedded within another field, the healthcare system. Educators must apply and adapt theory and evidence from the broader field of education within the context of busy clinical service and environments ill-suited to deliberate teaching. While subject to regulation as part of higher education that focuses on the quality of education, much of the learning is based on immersion of learners in healthcare delivery, where the focus of different regulatory processes is the safety and quality of health care. Many regard the relationship between the two systems as symbiotic, but this is a complex environment where the needs of learners and patients, and indeed the broader society, might not be the same.

Differences in understanding of evidence is part of the complexity. In health care the focus is often on causation and effectiveness from scientific experimental research, but random sampling, blinding, placebos and control groups are rarely possible or even ethical in education research. Education has a strong theoretical base, relying on philosophy, history, social sciences and, more recently, both qualitative and quasi-experimental research, as is appropriate for the more complex research questions about multi-factorial influences. Health professions education reflects this theory and evidence base, but delivery relies on centuries of experience with 'traditional' didactic, expert-informed and apprenticeship approaches. This journal publishes work that builds theory and evidence to support health professions education, so on its 25th anniversary it is appropriate to reflect on progress.

While there are influential thought leaders in both the broader field of education (Bloom 1954; Knowles 1975; Schon 1984) and healthcare (Gawande 2007), advances in health professions education are driven more often by ideas and theory brought in by educators from other professions who are immersed in health professions education. While not necessarily understanding clinical practice, asking questions from 'outside' may be advantageous. Recent examples include Schmidt, Norman and Van der Vleuten, whose contributions have shaped much of the recent approach to curriculum design and assessment of learning (Schmidt et al. 2011; Norman 2002; Van Der Vleuten and Schuwirth 2005). Educators with health professions qualifications often take leading roles in adapting and implementing newer ideas in the 'messy' real world of health care, such as Flexner, Barrows and Harden (Flexner 2011; Barrows 1996; Harden et al. 1984).

This article was written about 6 months into the COVID-19 pandemic, a major disruption to both healthcare and education systems. Disruption is known to be a major driver of change, producing entirely new business models or improving efficiency (Christensen 1997). Health professions educators responded rapidly to develop 'work-arounds', resulting in some innovative practices that may be sustainable long-term (Hays et al. 2020). Pragmatism may be the dominant force, but basing innovation on theory and evidence may be the key to longer term success. We have adopted the approach that, although the pandemic is of great interest in 2020, it is not the only disruption or influence on development. Therefore, 
we focus on how the theoretical and evidence base informs developments, including those associated with disruption.

We approach this as clinicians in different specialties and in senior roles in health professions education in three countries. RH is a rural general practitioner in Australia with additional qualifications in education and a record of establishing new or substantially revised medical programs in several countries. SR is a general internist and educationalist in the United States whose main focus is Postgraduate education and scholarship in medical education, and more recently has spearheaded a global community of mentors who facilitate conversations on teaching, learning and leading change during the COVID-19 pandemic. AH is a rheumatologist who led a young UK medical school delivering a highly integrated program with prominent community placements that had to be accelerated during the COVID-19 pandemic to contribute early graduates to the workforce. In combination therefore, we represent diverse contexts and experiences.

\section{The current status of pedagogy and practice}

Before considering change, it may be important to understand from what change might emerge. Health professions education is currently within higher education, usually in universities, delivered with a mixture of theoretical underpinnings and pragmatism. Programs follow purposefully designed curricula that reflect the goals and desired graduate learning outcomes and are developed in collaboration with employers and regulators (Thomas et al. 2015; Hays 2007). 'Explicit', 'product-oriented' curriculum models are common (Smith 2000). Learning outcomes are stated, ideally written as specific, measurable, attainable, relevant and 'time-bound' (Bloom 1954; Chatterjee and Corral 2017). Curriculum content is organised conceptually in a way that makes sense to participants. For example, traditional education domains relate to knowledge (cognitive), skills (psychomotor) and behaviours (affective) (Bloom 1954), not far from the Aristotelian concept of theory, practice and product (Smith 2000). In healthcare education, domains become more complex because of the clinical context, with more domains being added to incorporate clinical practice, interprofessional team-based care and population health. An emphasis on professionalism is a recent development, although this is a complex construct that should not rely only on professional norms (Martimianakis et al. 2009). Another approach that is gaining popularity is to group content by roles, for example, Medical Expert, Communicator, Collaborator, Manager, Health Advocate, Scholar, and Professional (Frank and Danoff 2007).

Curriculum development models are available to guide the process of learning. One example is the SPICES model, which emphasises student centredness, problem-orientation, integration, community delivery and a balance of core and elective components (Harden et al. 1984). Some form of smaller group, interactive, student-centred learning is now common in case-, problem- or team-based methods (Barrows 1996; Hrynchak and Batty 2012). Integration of curriculum content is common, driven by some theoretical justification of improved information recall (Brauer and Ferguson 2014). However, the term is used variably and some disciplines believe that their importance is diminished (Hays 2015; Bolender et al. 2013). Clinical placements now often utilise non-hospital and community settings (Hays 2007).

A variety of learning methods are employed to suit different learning preferences, which are described differently. One is the VARK model—visual, auditory, read/write and kinaesthetic - and its variations (Fleming and Mills 1992). There is also the activist, theorist, 
pragmatist and theorist approach developed by Honey and Mumford (Honey and Mumford 1992), based on Kolb's learning cycle theory and grounded in experiential learning (Kolb 1984). Blended learning methods are becoming commonplace, combining face-to-face and online learning resources (Bonk and Graham 2005).

The theoretical basis of clinical learning is more complex, leaning more on vocational learning theory, which is based on adult learning principles (Knowles 1975), but having to adjust to the ebb and flow of clinical service demands. Apprenticeship has existed in some form for centuries and has been drawn into social theories of learning, emphasising transformative, lifelong learning (Guile and Young 1988). From this has emerged the concept of communities of practice, a social system approach based on relationships in the workplace (Wenger 1999). Health care systems are complex and individuals can be part of more than one community of practice. A strong literature in work-integrated learning (WIL) is developing to support the practice (Cooper et al. 2010). Learners in the health professions contribute to genuine health care outcomes under graded supervision (Halpern and Detsky 2014), often following preparation and 'safety checking' in simulation prior to deliberate practice (Motola et al. 2013). Employers emphasise workplace readiness, regulators emphasise safety and quality and patients, in addition, want choice and convenience. There is tension between the traditional time-based and competency-based approaches (Carraccio et al. 2016). Part of this discussion is about moving from relatively simple outcomes to more complex meta-competencies that define professional activities expected of learners at significant transitional stages, known as entrustable professional activities or EPAs (Chen et al. 2015).

Ideally, assessment practices are aligned with program goals, learning outcomes at each stage of the program and learning methods (Biggs 2003). The approach to assessment is currently about finding the right balance between assessment 'for learning', with frequent, specific feedback and assessment 'of learning', with strictly controlled processes to support defensible decisions. Knowledge assessment should focus on ability to access, interpret and apply reliable sources of knowledge and clinical guidance on a "just in time" basis. Where possible, assessment is of performance rather than competence or knowledge (Miller 1990), so workplace-based assessment is becoming more common. More recently, the concept of measuring professional identity has emerged (Cruess et al. 2016). Increasingly, assessment is recognised as requiring a systematic, rather than episodic, approach (Norcini et al. 2018). One example is programmatic assessment, where a wider range of attributes are assessed using smaller, more focused and more frequent assessments by more assessors and a wider range of methods and tools (Van Der Vleuten and Schuwirth 2005). The traditional dependence on using numerical ratings to assess learners is being supplemented by consideration of meaningful narrative data. This approach may assess better 'meta-competencies' needed for complex tasks, including components of humanism and professionalism. This can be difficult to implement because of resource needs and costs, as well as uncertainty about how much information from what sources provides the best decisions (de Jong et al. 2019).

Finally, recognition of medical programs has become a major issue. Most major accreditation systems focus on graduate outcomes, allowing different approaches for their achievement. With the global expansion of medical education and increasing mobility of medical graduates across international borders, some form of agreement is required about transferable graduate outcomes and education processes. Recognition of primary medical training will soon be awarded only to graduates of medical programs that are judged to meet standards that can be mapped to those of the World Federation of Medical Education (WFME) and are accredited by a national agency that is recognised by the WFME (World Federation 
of Medical Education 2015). This confers eligibility to be included on the World Directory of Medical Schools (FAIMER 2016), although other requirements may remain for recognition of graduates outside of their country of training.

In summary, contemporary medical education has strong roots in education theory, which during clinical training is adapted in a pragmatic way by fluctuations in clinical service workloads to meet the expectations of employers, regulators and patients. The influence of professional norms is strong, but subject to influence from students, patients, employers and regulators.

\section{Educating the health professionals of tomorrow}

Looking forward is inherently speculative, so rather than predict the future we present current pressures for change that may influence future development, indicating where there are gaps in theory and evidence to guide that development. We describe a vision of the future of health professions education, categorised under three main headings: values that need to be emphasised (social contract, humanism, professionalism), needs that require a shift in educational approaches (new clinical care models), and artefacts (application of technology, telehealth, genetics etc in provision of clinical care).

\section{Values that need to be emphasised through social contracts}

A social contract can be defined as a relationship, often unwritten, between the medical profession and the society it serves. According to Cruess and Cruess:

Society granted physicians status, respect, autonomy in practice, the privilege of self-regulation, and financial rewards on the expectation that physicians would be competent, altruistic, moral, and would address the health care needs of individual patients and society. This "arrangement" remains the essence of the social contract.

(Cruess and Cruess 2014)

Health professions education has a significant role in ensuring that future healthcare professionals fulfil this contract to the best of their ability. Yet, medical education has often been accused of being out of touch with or ill-informed about the needs of society, leading to disparities between what students are prepared for and societal needs and social determinants of health (Wayslenski et al. 1997). These disparities widen as knowledge of science and availability of technology and investigations expand. Thus, it would be important for future healthcare professionals to engage with members and leaders of the community they serve, assess their needs firsthand, and learn to provide care that emphasises preventive health and incorporates social determinants of health. For this to occur, health professions education leaders need to prioritise these skills in the curriculum and create opportunities for students to learn about the community and their needs, as well as do rotations with their public health colleagues. Additionally, having a formal curriculum would not be effective unless these objectives are aligned with the behaviours modelled by educators and leaders; these contribute to a hidden curriculum (Martimianakis et al. 2015; Hafferty et al. 2015). This is particularly important because of research reports suggesting that medical students' empathy declines as they progress through medical school training (Chen et al. 2007), 
although some educators emphasise that careful student selection and training can preserve student empathy (Hegazi and Wilson 2013).

An important aspect of social accountability of the healthcare professions is to recognise disparities in healthcare delivery and work towards ensuring health equity. The DISCuSS model (Diversity, Identify, Search, Create module with community engagement, Sustainability, Social accountability) is one approach to create a community-engaged iterative curriculum for students (Goez et al. 2020), developed to specifically improve the care of marginalised populations. Community-centred and community-engaged pedagogical initiatives are needed in order to meet the healthcare needs of society and fulfil obligations of the social contract, by ensuring that the 'patient perspective' is incorporated into decision making. In response to the Lancet Commission on Education of Health Professionals for the 21st Century (Frenk et al. 2010), it has been proposed that community-engaged medical education (CEME) can better meet healthcare needs of communities and enhance healthcare equity (Strasser et al. 2015). Patients (as stewards of their own health) and community leaders (better placed to judge community healthcare challenges) should actively engage in making choices, contributing to decisions and providing feedback to both individual healthcare professionals and the healthcare system.

Many leaders in medicine believe that professionalism and professional identity formation form the anchor of the social contract. Applying social contract concepts to professionalism can facilitate discussions on the greatest challenges to healthcare and increase understanding of the relevance of professionalism to clinical care through role modelling, assessment and remediation (Cruess and Cruess 2008). However, a rigid view of the attributes of professionalism may actually be a barrier to understanding and teaching it (Harris 2017), so assessment of performance needs to move away from a narrow focus on numerical data.

Further, the role of students in quality improvement is changing and could be made more explicit. Students may observe practices that could be improved, perhaps quite simply, or may observe an error made by a more senior colleague. Current reporting systems can be difficult, despite 'whistle-blower' safeguarding. Recently, publicity about highly publicised issues of quality of care in NHS providers (General Medical Council, Francis 2013) has led to a change in expectations by UK regulators. There is now an explicit requirement that health education institutions ensure that the healthcare environments in which students are placed deliver safe patient care and that there are clear pathways for students to raise concerns about care provision (General Medical Council 2016).

A critical pedagogic approach can help foster social accountability among its learners. Adopting critical consciousness as an intellectual construct in the pedagogy promotes acknowledgement of flaws in the current system of education and encourages change, supporting the embedding of these behaviours in day to day practice and workplace culture (Manca et al. 2020).

\section{Working with students and patients}

It is worth thinking about how the social contracts with students and patients may evolve. The traditional approach in education is 'top-down', where experts pass on their knowledge and wisdom to learners. This model fits well into the hierarchical structure of health professions and employment in healthcare systems. To be successful, students must survive two major personal and professional transitions where education and health care systems 
overlap. The first is the transition from campus-based learning to clinical immersion. Almost overnight, students are expected to look, behave and perform like the healthcare professionals they aspire to become, but spend most of their time observing and discussing care provided by others, with little or no responsibility for outcomes. Then, again almost overnight, graduates are expected to perform important workplace roles and take responsibility for their actions under graded supervision from the bottom of a new hierarchy. Novices at both transitions are not necessarily welcome, as work 'efficiency' suffers if delivery slows to teach and supervise correctly. Many learners do not feel adequately prepared and mental health problems appear more common (Karp and Levine 2018). At its worst, the journey is one of passively following the 'rules' of the health care system while working out how to learn enough to pass examinations. Meanwhile, patients are often passive instruments of instruction, providing the material to be learned, sometimes with little engagement in learning or healthcare processes.

Society is changing, including an expectation by people of more control of their information content and processes. Increasingly, students and patients want to be recognised as 'experts' in their own experiences and so become 'co-creators' of educational programs in which they are more partners than mere participants (Bovill 2019).

Both education and healthcare systems are responding to demands from 'bottom-up' and 'sideways-in' influences. Patients want the best health care and many want to contribute more actively to teaching and assessment. Students want a more personalised learning pathway that provides greater choice and blends different learning approaches (Sampson and Karagiannidis 2002). There are also consistent reports that students are not satisfied with current assessment feedback (Harrison et al. 2016). While programs have responded by providing more information as feedback, is this the right information and does it have sufficient meaning? Broader contemporary issues also directly impinge on the student's experience. The recent 'Black Lives Matter' movement has increased recognition of continuing discrimination against students of colour-by faculty, other students and by patients (Rao 2020). Preparing all students for practice in healthcare settings in which prejudicial behaviours by vulnerable patients may still exist remains an important element of the social contract (British Medical Association 2020).

\section{Working with employers and regulators}

The relationship with employers is complex. Health professions education provides the workforce needed to deliver health care, but the clinical context, content and process 'belong' to the clinical providers. Tensions arise from the different perspectives of education (clinical immersion, feedback and assessment for learning) and health (work-readiness, efficiency, safety and quality, recruitment) systems. Even senior students may contribute little formally to patient care, although the recent early graduation and assistantship roles for senior students during the COVID-19 pandemic illustrate a potential to allow senior students formal roles that might ease the workplace transition. On the other hand, are there risks in combining employer/educator roles?

The role of the regulator in influencing the nature and content of health professions education may require review. Regulators' mandates are usually couched in terms of protecting patient safety. Whilst that role is clearly essential, does this restrict curriculum innovation? For example, medical graduates must possess a wide range of knowledge and skills across much of the spectrum of medical practice, with the implied potential to enter any 
postgraduate specialty, yet often contribute little to direct patient care. Does this waste scarce clinical resources? Could intensifying and narrowing clinical experience to specialty choice commence sooner, either at graduation (as in North America) or even during primary medical training? Would this remove barriers for some applicants with certain disabilities that limit achievement of some generic graduate outcomes that are not required for their intended specialty careers? Changes to regulations for health professional education may make more complex the recognition across jurisdictions at a time when pressure is growing for greater international mobility.

\section{Needs: evolving clinical care models}

\section{Clinical service delivery models}

Clinical service delivery models continue to evolve. The focus for the last 20 years has been shifting services from hospitals to the community. Same day service models now provide most care episodes in many healthcare systems. Modern hospitals place emergency, critical care, investigation, procedure and short stay (chairs or beds) services at the centre, with longer stay wards attached for those too ill to go home. Initial work-up and followup care is being diverted to ambulatory services in the community, for a combination of reasons, such as cost control, patient convenience and equivalence of outcomes. The next stage of service configuration may be moving more care to patients' homes. Remote sensing technology is already being embedded in mobile device apps and this trend will continue. The greatest potential is in chronic disease management, where data such as weight, blood pressure and home readings of an increasing range of in-home lab tests will provide data for interpretation by telehealth consultations. Community health centres, including general/family practice clinics may become coordination centres with much less patient contact. Only the very ill will be found in hospitals and community clinics will focus on the moderately ill. The not yet ill and the recovering may not be found in either hospitals or community clinics. This may be safer than bringing currently well patients with complex co-morbidities to facilities where sick people congregate. Is experience in other industries relevant, for example in shopping? Are face-to-face clinic appointments like 'High St' shopping and hospitals and investigation centres like 'warehouse' centres, with most retail transactions moving online from home direct to warehouses?

This re-configuration may have a significant impact on health professions education, because health care will become much more dispersed. Health professions education follows health care delivery and providing the same degree of workplace immersion and supervision at the point of care may be difficult. Learners may be placed more often with ambulatory services and attend patient homes, which is potentially a deeper but narrower exposure to presenting complaints and pathology. Learners may participate in processing of remote sensing data and coordination of care, but with less face-to-face contact. Hospitals may become less relevant to the more general nature of undergraduate health professional education. Health professionals may need different skills in communication, managing multi-source information and training in the use of technology including shared decision making through telehealth. How will this affect learning and its assessment of practical and clinical application of knowledge? How much can simulation bridge any gaps in learning and assessment in the emerging clinical service models? 
Clinical care is also likely to become more interprofessional, with outcomes more dependent on teamwork than individuals. This may require a differently configured workforce. Should there be more generalists in all health professions, coordinating access to narrower specialty services, or should patients be provided more direct access to narrower specialty services? Strong primary care models have been associated with improved equity of access and lower cost (Starfield 2011), but how well will the current hierarchical approach manage an increased range of highly specialised and even personalised diagnostic and management strategies based on new technology? What roles can clinicians play in training and supervising of students in other health professions? This already happens to an extent, but how does it affect professional identity formation?

\section{Artefacts: technology, Al, genetic information and personalised medicine}

Advancing technology is inherent in most developments, but whether technology is a driver or servant of change is much debated. For example, it has been possibly technically for several years to deliver entire education programs online, but this has not been popular with students or teachers and so has not been adopted widely. The extent to which education benefits from social interaction is unclear, although it may be necessary to learn and deliver patient-centred care. The rapid expansion into online methods during the COVID19 pandemic happened because the technology was available and adaptation was both possible and essential, but it is too early for evaluation of effectiveness or outcomes.

It may not be long before all patients are gene-sequenced and 'personalised' medicine becomes the norm. This opens an interesting conversation about curriculum content, where much time is taken up with 'old' but important science, such as anatomy. Curriculum developers need to find time for 'new' science, such as genomics and immunology, where the most impact on human health may lie. Achieving the right balance will be challenging.

The role of artificial intelligence (AI) systems is not yet clear. It is likely that AI will help to develop algorithms, interpret data and inform better and more consistent diagnostic formulation which may prevent omission of key diagnostic and therapeutic steps. Direct roles in patient management are less likely, although technology will become more important by providing more robotic surgical assistance, as an example. There is currently little evidence to guide education development, although one benefit may be automatic item generation (AIG) in assessment (Gierl et al. 2019), along with computer-based tailored testing and feedback provision.

\section{Disruption}

Disruption caused by the COVID-19 could continue for some time. We may have to adopt 'permanent' enhanced infection control, with minimisation of travel of patients, clinicians and teachers between health care facilities. There are other potential disruptions, both regional and global, such as further pandemics, IT system failure (cyberattacks, sunspot activity etc), earthquakes, floods, famine and fires. This emphasises a need for agility to not just respond, but to respond early and rapidly. Can learning from disruption lead to 'future proofing'?

The concept of 'sustainable' health care and health professional education is gaining credibility (Tun 2019). Climate change is much debated and is of great interest to students, as they may have to manage health care amidst substantial impact. How will increasing migration 
from low-lying communities and nations affect health and health care? Will current larger cities build stronger defences, as in New Orleans and Venice, and how effective will these defences be? What impact will there be on poverty, overcrowding and infectious diseases? Public health thinking and training may increase in importance and public health medicine become a more attractive career choice.

\section{Research agenda for an evidence-based future?}

While pragmatism is likely to dominate responses in the short term to surrounding changes, innovation may be more sustainable if supported by theory and evidence. The following complex topics are priorities for research, requiring both qualitative and quantitative approaches.

1. What impact will increasing engagement of students, patients, employers and regulators have on determining graduate outcomes and career pathways that address emerging issues such as sustainable health care, climate change and advances in technology? This relates to the social contract that health professions education has with society.

2. How will likely changes to health care delivery affect learning and assessment? As some services move 'closer to home', potentially increasing the 'compartmentalisation' of health care, will basing student learning and assessment in hospital or community services better prepare them to achieve agreed graduate outcomes?

3. How will learners and employers adapt to programs delivered more often by remote means, with more learning and assessment delivered by simulation, discussions without patients and increased technology? The impact of social interaction on quality (enjoyment and effectiveness) of learning requires improved understanding.

4. How can pressures on learners be reduced so that the transitions to different levels of clinical contexts and responsibility are less stressful? What formal roles and what degree of responsibility could senior students be allowed prior to graduation? How would these roles be supervised and supported?

5. How can learners' input be incorporated into co-creation of the educational environment and learning opportunities? What level of ownership should learners assume for their ongoing professional development?

The effective addressing of our suggested research questions is predicated on the successful engagement of scientists and health professionals with researchers from other backgrounds, including education, psychology, the social sciences, economics, information management and engineering. While this already happens to some extent, governments and funding bodies need to send stronger signals to health researchers that the scope of interdisciplinary research should be much broader if the important, yet complex questions are to be addressed. If such investment takes place, we can have some confidence in the conscious development of the science of health professions education with resulting benefit to students, patients and the broader public. 


\section{Conclusion}

In this, the anniversary issue of the Journal, it is timely to reflect on the science and approach to the education of health professionals. Current health professions education is a product of mainstream educational philosophy, theory, principles and practice that are applied in a busy clinical service context where patient safety, quality of care and efficiency often come first. Education and service delivery exist in a complex relationship that is mutually dependent but sometimes strained by conflicting pressures. While this arrangement has arguably worked well, both education and healthcare systems continue to evolve in the face of changes in knowledge, skills, population demographics and social contracts. New service delivery models are emerging and health professions educators must listen to the voices of regulators, employers, students and patients. Other external factors, such as pandemics and climate change, are disruptions that may drive innovations that result in lasting change. Emerging technology has some capacity to support the new clinical and service delivery models, but the optimal balance of remote and in-person clinical care that enhances efficiency without increasing diagnostic errors is yet to be identified. While the theoretical basis of health professions education remains strong, finding evidence of the effectiveness of newer delivery models should be a priority. Components and outcomes of health services are so broad that much more extensive interdisciplinary research should be fostered to address the complex questions and problems that will continue to arise.

\section{References}

Barrows, H. (1996). Problem-based learning in medicine and beyond: A brief overview. New Directions in Teaching and Learning, 68, 3-12.

Biggs, J. (2003). Aligning teaching and assessing to course objectives. Teaching and learning in higher education: New trends and innovations (Vol. 2, pp. 13-17). University of Aveiro.

Bloom, B. (1954). Taxonomy of educational objectives. The classification of educational goals. London: Longmans, Green.

Bolender, D., Ettarh, R., Jerrett, D., \& Laherty, R. (2013). Curriculum integration = course disintegration: What does this mean for anatomy? Anatomical Sciences Education, 6, 205-208. https://doi. org/10.1002/ase. 1320 .

Bonk, C., \& Graham, C. (2005). The handbook of blended learning: Global perspectives, local designs. New York: Wiley.

Bovill, C. (2019). Co-creation in learning and teaching: The case for a whole-class approach in higher education. Higher Education, 79, 1023-1037. https://doi.org/10.1007/s10734-019-00453-w.

Brauer, D. G., \& Ferguson, K. J. (2015). The integrated curriculum in medical education: AMEE Guide Number 96. Medical Teacher, 37, 312-322. https://doi.org/10.3109/0142159X.2014.970998.

British Medical Association. (2020). A charter for medical schools to prevent and address racial harassment. London: BMA Retrieved from https://www.bma.org.uk/media/2030/bma-med-school-charterimplementation.pdf.

Carraccio, C., Englander, R., Van Melle, E., ten Cate, O., Lockyer, J., Chan, M.-K., Frank, J. R., \& Snell, L. (2016). Advancing competency-based medical education: A charter for clinician-educators. Academic Medicine, 91, 645-649. https://doi.org/10.1097/ACM.0000000000001048.

Chatterjee, D., \& Corral, J. (2017). How to write well-defined learning objectives. Journal of Education in Perioperative Medicine, 19, E610 Retrieved from https://www.ncbi.nlm.nih.gov/pmc/articles/PMC59 44406/.

Chen, D., Lew, R., Hershman, W., \& Orlander, J. (2007). A cross-sectional measurement of medical student empathy. Journal of General Internal Medicine, 22, 1434-1448.

Chen, H., van den Broek, W., \& ten Cate, O. (2015). The case for use of entrustable professional activities in undergraduate medical education. Academic Medicine, 90, 431-436. 
Christensen, C. M. (1997). The innovator's dilemma: When new technologies cause great firms to fail. Boston: Harvard Business School Press.

Cooper, L., Orrell, J., \& Bowden, M. (2010). Work integrated learning: A guide to effective practice. Abingdon: Routledge.

Cruess, R., \& Cruess, S. (2008). Expectations and obligations: Professionalism and medicine's social contract with society. Perspectives in Biological Medicine, 51, 579-598.

Cruess, R., \& Cruess, S. (2014). Updating the Hippocratic Oath to include medicine's social contract. Medical Education, 48, 95-100.

Cruess, R., Cruess, S., \& Steinert, Y. (2016). Amending Miller's pyramid to include professional identity formation. Academic Medicine, 1, 80-185. https://doi.org/10.1097/ACM.000000000000091.

de Jong, L. H., Bok, H. G., Kremer, W. D., \& van der Vleuten, C. P. (2019). Programmatic assessment: Can we provide evidence for saturation of information? Medical Teacher, 41, 678-682.

Fleming, N., \& Mills, C. (1992). Not another inventory, rather a catalyst for reflection. To Improve the Academy, 11, 137-143.

Flexner, A. (2011). Medical education in the United States and Canada. New York: Carnegie Foundation.

Foundation for Advancement of International Medical Education and Research (FAIMER). (2016). Directory of Organisations that Recognize/Accredit Medical Schools (DORA). Retrieved July 2020, from https://www.faimer.org/resources/dora/index.html.

Frank, J., \& Danoff, D. (2007). The CanMEDS initiative: Implementing an outcomes-based framework of physician competencies. Medical Teacher, 29, 642-647. https://doi.org/10.1080/0142159071 746983.

Frenk, J., Chen, L., Bhutta, Z. A., Cohen, J., Crisp, N., Evans, T., Fineberg, H., Garcia, P., Ke, Y., Kelly, P., Kistanasamy, B., Meleis, A., Naylor, D., Pablos-Mendes, A., Reddy, S., Scrimshaw, S., Sepulveda, J., Serwadda, D., \& Zurayk, H. (2010). Health professionals for a new century: Transforming education to strengthen health systems in an interdependent world. Lancet, 376, 1923-1958.

Gawande, A. (2007). Better: A surgeon's notes on performance. New York: Metropolitan Books.

General Medical Council. (2016). Achieving good medical practice: Guidance for medical students. London: General Medical Council. Retrieved July 2020, from https://www.gmc-uk.org/-/media/ documents/achieving-good-medical-practice-0816_pdf-66086678.pdf.

General Medical Council, Francis, R. (2013). Final report mid staffordshire NHS Foundation trust public inquiry. London: General Medical Council. Retrieved July 2020, from https://webarchive.natio nalarchives.gov.uk/20150407084231/http://www.midstaffspublicinquiry.com/report.

Gierl, M., Lai, H., \& Zhang, X. (2019). Automatic item generation. In M. Khosrow-Pour (Ed.), Advanced methodologies and technologies in modern eduction delivery. Hershey: IGI Global. https ://doi.org/10.4018/978-1-5225-7365-4.ch016.

Goez, H., Lai, H., Rodger, J., Brett-MacLean, P., \& Hillier, T. (2020). The DISCuSS model: Creating connections between community and the curriculum-A new lens for curricular development in support of social accountability. Medical Teacher, 42, 1058-1064. https://doi.org/10.1080/01421 59X.2020.1779919.

Guile, D., \& Young, M. (1988). Apprenticeship as a conceptual basis for a social theory of learning. Journal of Vocational Education and Training, 50, 173-193.

Hafferty, F. W., Gaufberg, E. H., \& O'Donnell, J. F. (2015). The role of the hidden curriculum in 'on doctoring' courses. AMA Journal of Ethics, 17, 130-139.

Halpern, S., \& Detsky, A. (2014). Graded autonomy in medical education-managing things that go bump in the night. New England Journal of Medicine, 370, 1086-1089.

Harden, R., Sowden, S., \& Dunn, W. (1984). Educational strategies in curriculum development: The SPICES model. Medical Education, 18, 284-297. https://doi.org/10.1111/j.1365-2923.1984.tb010 24.x.

Harris, J. M. (2017). It is time to cancel medicine's social contract metaphor. Academic Medicine, 92, 1236-1240.

Harrison, C. J., Konigs, K. D., Dannefer, E. F., Schuwirth, L. W. T., Wass, V., \& Van der Vleuten, C. P. M. (2016). Factors influencing students' receptivity to formative feedback emerging from different assessment cultures. Perspectives on Medical Education, 5, 276-284.

Hays, R. (2015). Integration in medical education: What do we mean? Education for Primary Care, 24, 151-152. https://doi.org/10.1080/14739879.2013.11494358.

Hays, R. B. (2007). Community-oriented medical education. Teaching and Teaching Education, 23, 286-293. 
Hays, R., Jennings, B., Gibbs, T., Hunt, J., \& McKay, K. Impact of the COVID-19 pandemic: The perspectives of health professions educators. MedEdPublish, 2020. https://doi.org/10.15694/ mep.2020.000142.2.

Hegazi, I., \& Wilson, I. (2013). Maintaining empathy in medical school: It is possible. Medical Teacher, 35, 1002-1008.

Honey, P., \& Mumford. (1992). The manual of learning styles (3rd ed.). Maidenhead: Honey.

Hrynchak, P., \& Batty, H. (2012). The educational theory basis of team-based learning. Medical Teacher, $34,796-801$.

Karp, J. F., \& Levine, A. S. (2018). Mental health services for medical students-Time to act. New England Journal of Medicine, 379, 1196-1198.

Knowles, M. S. (1975). "Self-directed learning”: A guide for learners and teachers. New York: Cambridge Books.

Kolb, D. (1984). Experiential learning: Experience as a source of learning (2nd ed.). New York: Prentice-Hall.

Manca, A., Gormley, G. J., Johnston, J. L., \& Hart, N. D. (2020). Honouring medicine's social contract: A scoping review of critical consciousness in medical education. Academic Medicine, 95, 958-967.

Martimianakis, M., Maniate, M., \& Hodges, B. (2009). Sociological interpretations of professionalism. Medical Education, 43, 829-837. https://doi.org/10.1111/j.13652923.2009.03408.x.

Martimianakis, M. A., Michalec, B., Lam, J., Cartmill, C., Taylor, J. S., \& Hafferty, F. W. (2015). Humanism, the hidden curriculum and educational reform: A scoping review and thematic analysis. Academic Medicine, 90, S5-S13.

Miller, G. E. (1990). The assessment of clinical skills/competence/performance. Academic Medicine, 65, s63-s67.

Motola, I., Devive, L., Chung, H., Sullivan, J., \& Issenberg, S. (2013). Simulation in health care education: A best evidence practical guide. AMEE Guide No. 82. Medical Teacher, 35, e1511-e1530.

Norcini, J., Anderson, B., Bollelo, V., Burch, V., Costa, M., Divivier, R., Hays, R. B., Roberts, T., Palacios Mackay, M., \& Swanson, D. (2018). 2018 consensus framework for good assessment. Medical Teacher, 40, 1102-1109. https://doi.org/10.1080/0142159X.2018.1500016.

Norman, G. (2002). Research in medical education: Three decades of progress. British Medical Journal, 324, 1560 Retrieved from https://www.bmj.com/content/bmj/324/7353/1560.full.pdf.

Rao, M. (2020). Racism in medicine: Why equality matters to everyone. British Medical Journal, 368, m530. https://doi.org/10.1136/bmj.m530.

Rastegar, D. (2004). Health care becomes an industry. Annals of Family Medicine, 2, 79-83. https://doi. org/10.1370/afm.18.

Sampson, D., \& Karagiannidis, C. (2002). Personalised learning: Educational, technological and standardisation perspective. Interactive Educational Multimedia, 4, 24-39 Retrived from http://revistes. ub.edu/index.php/IEM/article/view/11738/14548.

Schmidt, H. G., Rotgans, J. I., \& Yew, E. H. J. (2011). The process of problem-based learning: What works and why. Medical Education, 45, 792-806.

Schon, D. (1984). The reflective practitioner: How professionals think in action. Oxford: Taylor and Francis.

Smith, M. (2000). Curriculum theory and practice. Retrieved from http://www.fnbaldeo.com/EDCI\%20 547\%20-\%20March\%202018/Resource\%20Materials/Curriculum\%20Theory\%20and\%20Practice .pdf.

Starfield, B. (2011). Challenges to primary care from co- md multi-morbidity. Primary Health Care Research \& Development, 12, 1-2. https://doi.org/10.1017/S1463423610000484.

Strasser, R., Worley, P., Cristobal, F., Marsh, D. C., Berry, S., Strasser, S., \& Ellaway, R. (2015). Putting communities in the driver's seat: The realities of community-engaged medical education. Academic Medicine, 90, 1466-1470.

Thomas, P., Kern, D., Hughes, M., \& Chen, B. (2015). Curriculum development for medical education: A six-step approach. Baltimore: Johns Hopkins University Press.

Tun, S. (2019). Fulfilling a new obligation: Teaching and learning of sustainable healthcare in the medical education curriculum. Medical Teacher, 41, 1168-1171. https://doi.org/10.1080/01421 59X.2019.1623870.

Van Der Vleuten, C. P. M., \& Schuwirth, L. W. T. (2005). Assessing professional competence: From methods to programmes. Medical Education, 39, 309-317. https://doi.org/10.111 1/j.1365-2929.2005.02094.x.

Wayslenski, D., Byrne, N., \& McRobb, B. (1997). The social contract in medical education. Medical Education, 31, 250-258. 
Wenger, E. (1999). Communities of practice: Learning, meaning and identity. Cambridge: Cambridge University Press.

World Federation of Medical Education. (2015). Basic medical education WFME global standards for quality improvement. The 2015 revision. Denmark, France: World Federation for Medical Education; 2015. Retrieved from https://wfme.org/download/wfme-global-standards-for-quality-impro vement-bme/.

World Health organisation. (2020). Goals and objectives. Retrieved from https://www.who.int/healthprom otion/about/goals/en/.

Publisher's Note: Springer Nature remains neutral with regard to jurisdictional claims in published maps and institutional affiliations. 